management, unwearied patience, scientific attainments, and disinterested generosity, the Principia might never have been published".

The book before us does not call for detailed review. It is a model of its kind, and, while not a life of Halley, it brings together a mass of material which, interesting in itself, should prove of immense value to any future biographer of Halley. The volume contains a memoir, possibly written by Martin Folkes, an éloge by de Mairan, a chronological list of Halley's correspondence, and a large quantity of hitherto unprinted letters and papers arranged in order of date. An appendix of about a hundred pages is concerned with a valuable series of Halleiana. Scholarly, relatively inexpensive, and well produced, the book should find a place on the shelves of every serious student of astronomy.

\title{
Recent Radio Research
}

$\mathrm{T}$ HE Department of Scientific and Industrial Research has recently issued the report of the Radio Research Board for the year 1931,* summarising work carried out during the year. The investigations described are concerned mainly with the fundamental study of the electrical state of the upper atmosphere and its influence on the propagation of radio waves of all frequencies; the principles and improvements of method of radio direction-finding; the study of atmospherics from the point of view of radio communications and meteorology ; the development of radio frequency standards; and the improvement of electrical measurements at high frequencies. This work is carried out mainly at the Radio Research Station, Slough, and at the National Physical Laboratory, Teddington, but a certain amount of research has also been fostered at universities.

The study of the ionisation of the atmosphere and its influence on the propagation of radio waves has been continued both by the frequencychange method which was originated in Great Britain by Prof. E. V. Appleton, and also by the pulseemission or group-retardation method, first developed by G. Breit and M. A. Tuve in the United States. To assist in this investigation, which includes the systematic collection of data on the electrical properties of the upper atmosphere, a special transmitting installation has been designed and is in course of construction at the National Physical Laboratory. Concurrently with the experimental work, a theoretical analysis is being made of the effect of the upper atmosphere on radio waves, and the mathematical formulæ are being evaluated numerically for typical cases, so that the results can be used by the practical radio engineer. In all this work the effect of the earth's magnetic field is being studied, the necessity for this having been confirmed in an interesting manner in the year under review by experiments carried out in the southern hemisphere under the Australian Radio Research Board.

The report describes also the extension of the study of wave propagation to wave-lengths of less than 10 metres. In the first instance, the transmission of these ultra-short waves along the earth's surface has been investigated, and from the resulting measurements, values of the effective

* Department of Scientific and Industrial Research. Report of the Radio Research Board for the Year 1931. Pp. iv + 123. (London: H.M. Stationery Office, 1932.) 2s, net. conductivity and dielectric constant of the earth have been obtained by wave-lengths between $1 \cdot 6$ and 10 metres. In addition, experiments have been carried out on a wave-length of 5.5 metres over a distance of 44 miles. In these experiments the absence of any downcoming radiation from the upper atmosphere was clearly indicated, and it was apparent that only the direct or ground waves were effective in securing communication, although the reception obtained was definitely not confined to the rectilinear or so-called 'optical' path between transmitter and receiver. Certain diurnal variations were found on hot, sunny days which were not experienced on dull, autumn days. The theoretical and practical investigation of the whole subject is being continued. Progress is also recorded in the study of improved means for generating electron oscillations giving rise to wave-lengths of less than 1 metre.

The report indicates that considerable progress has been made towards the development of the perfect direction-finder for medium wave-lengths, free from errors caused by downcoming waves occurring mostly at night. The behaviour of direction-finders on shorter wave-lengths is being studied, and the application of the cathode ray oscillograph to a direct-reading instantaneous direction-finder has met with considerable success. This is undoubtedly due to the large amount of experience previously obtained in the use of these instruments in the study of atmospherics at the Radio Research Station.

In the present crowded state of the ether, it is specially important that every radio station should accurately maintain its allotted wavelength or frequency. The precise measurement of frequency, therefore, has become of great practical importance. The primary national standard of frequency is maintained at the National Physical Laboratory, and, as the report explains, is based on a tuning-fork maintained in continuous and steady vibration. The rate of vibration of the standard tuning-fork is now directly referred to that of an astronomical clock by an electrical arrangement, and can be obtained accurately to within one part in ten million. Experiments are in progress to determine the shortperiod constancy of the fork, that is, the constancy for one or two minutes at a time. It is not easy to compare frequencies to an accuracy of one part 
in a hundred million during an interval of only one minute, but such tests as have already been made indicate that the fluctuations due to the action of the thermal regulation are less than one part in a hundred million.

"Sufficient experience has now been accumulated," the report says, "to enable the statement to be made that properly designed and steadily operated tuning-forks form a primary frequency standard of reliability of about one part in ten million, a result fully equal to that of the best pendulum clocks. It is an interesting fact that the slight earthquake experienced in the south-east of England on June 7, 1931, caused a small change in rate of the pendulum clock of about four parts in ten million, which was revealed on the tuningfork chronograph, the tuning-fork being unaffected by the shock."
It has now become necessary to develop apparatus to resolve the differences between the tuningfork and the clock to enable short period fluctuations to be accurately observed. For this purpose radial vibrations of a small quartz crystal very carefully cut in the form of a ring are used to control the oscillation of a valve generator. The experiments carried out give good hope that a standard which is permanent and accurate to one part in a hundred million may be obtained in the near future.

The above review is by no means exhaustive of the contents of the report, which shows that the organisation controlled by the Radio Research Board continues the active pursuit of radio research and development, which in the past few years has placed Great Britain in a world-renowned position.

\section{Obituary}

\section{Prof. James Johnstone}

IAMES JOHNSTONE, the distinguished zoologist, oceanographer and philosopher, died at the age of sixty-two years at his home in Lochwinnoch on December 27 after a sudden attack of influenza. He appeared to have recovered from his former dangerous illness, so that his loss from an apparently accidental infection is felt the more keenly. He was not married.

There can be no doubt that he was a man of exceptional ability with an unusually wide knowledge of science; and a fearless and original thinker. Though reticent and even shy, "J. J.", as he was familiarly called, endeared himself to all those who had much to do with him by his kindly and sympathetic manner and his philosophical outlook on life's problems. It is characteristic of him that he was especially concerned about the future prospects of the junior staff and servants employed in his Department.

The future philosopher showed his naturalistic leanings as a boy when he roamed the country observing wild animals and collecting birds' eggs; he exhibited the urge of the 'vital impetus' which was to concern him greatly later-when as a young man he 'emerged' from the environment of a journeyman wood-carver by attending evening classes at Lochwinnoch and at Glasgow. By the encouragement of his teacher and coach, Robert Logan, and the facilities afforded by the local school board and the Board of Education, he was enabled at the late age of twenty-five to begin the study of the biological sciences at the Royal College of Science, London, mainly under Prof. G. B. Howes. Before graduating in 1900 at the University of London he had already written one paper on the thymus in marsupials and two on fisheries subjects.

On his appointment in 1898 as fisheries assistant to Sir William (then Prof.) Herdman on the research staff of the Lancashire and Western Sea
Fisheries Committee, Johnstone found a congenial environment; he threw himself with remarkable energy into studies in fisheries and the more general aspects of marine biology with such success that he had become a leading figure in British marine biology in 1908. This early success can be traced to his great interest in fisheries, to his unusually logical mind, and a great capacity for absorbing masses of data while perceiving and retaining a clear recollection of their interrelations, which he was able to expound in simple language. These faculties enabled him to bring together material on the growth and origin of "British Fisheries" (1905). The amassing of this material and his practical fishery experience placed him at once in a commanding position to give valuable support to the work of the newly instituted International Council for Fishery Investigations. The same faculties enabled him to produce an illuminating and classical work (1908) on "Conditions of Life in the Sea". This book was undoubtedly for many years a source of information and inspiration to the rising generation of marine biologists; in it he propounded a surprising proportion of the major problems which have been successfully investigated in recent years.

The basis of Johnstone's knowledge of fisheries lay in his experience in inshore and offshore work and the study of plankton in collaboration with his life-long friend, Andrew Scott. He also helped to lay the foundation for later successful work on the purification of shellfish. Marine bacteria were of great interest to him; his work led him to speculate on the existence in the sea of pathogenic types comparable with those found in terrestrial animals. He described a large number of malignant 'cancerous' tumours in fish, two of these being defined as of a "piscine tuberculosis" type, and accompanied these studies with extended investigations on parasites. His knowledge of this branch of pathology was associated with a vivid interest in human 'cancer', and its treatment by 